\title{
The Rise of Li' Ttledot: A study of citizenship education through game-based learning
}

Kenneth Y. T. Lim

Nanyang Technological University

Matthew Y. C. Ong

Ministry of Education, Singapore

\begin{abstract}
This paper reports data obtained from the use of a bespoke video game - The Rise of $L i^{\prime}$ Ttledot - in promoting a sense of participatory citizenship among young learners. The game was developed through funding awarded by the Ministry of Education in Singapore, and was piloted in a primary school. Citizenship education illustrates well the truism that the learning of values is better caught than taught. The game was situated within a wider curricular program which included the use of question cards in a post-gameplay dialogic session between teacher and students. The structure and scaffolds thusly afforded helped the pupils in the primary school to abstract from their experiences within the game, to relevant school-based examples.
\end{abstract}

\section{Introduction}

... no one is born a good citizen; no nation is born a democracy. Rather, both are processes that continue to evolve over a lifetime. Young people must be included from birth. A society that cuts off from its youth severs its lifeline... (Kofi Annan, 1998)

Citizenship education is perhaps one of the hardest concepts to discuss in the classroom. Good citizenship cannot really be taught, it has to be pondered about, experienced and practiced (Sim \& Print, 2005). However, it is difficult to re-create in classrooms authentic 'real world' scenarios through which to help learners develop appropriate civic values.

In Singapore, citizenship education is known as National Education. The latter rests on several core messages, one of which is "we must ourselves defend Singapore". In turn, this core message manifests itself primarily through the concept of Total Defence. In Total Defence, equal importance is attached to social, civil, psychological, economic and military defence. It emphasises that everyone has a part to play in defending the nation and that the responsibility of protecting our sovereignty cannot rest solely on the military's shoulders. However, from an adolescent's point of view, the default conception of Total Defence is to understand it in terms of its most tangible form military defence - at the expense of the other four pillars. This inability to see defence as beyond the responsibility of the military is akin to the perception of some students that English, maths and science are discrete disciplinary domains. The concept of Total Defence is flexible enough to integrate these subjects and still allow educators to promote awareness of National Education. This was the impetus behind the creation of 
the fictitious in-game island of $\mathrm{Li}^{\prime}$ Ttledot. $\mathrm{Li}$ ' Ttledot was designed to parallel Singapore in order for the island to be the focal point of the various scenarios around the five pillars of Total Defence. The Rise of $\mathrm{Li}^{\prime}$ Ttledot (hereafter abbreviated to Li' Ttledot) was therefore designed as an environment in which students could assume different identities and undertake tasks that would not yet be feasible for them 'in real life'. While playing $\mathrm{Li}^{\prime}$ Ttledot, every student would come to understand that his or her role is as important as any other in contributing to the success of the team.

As can be imagined, there have been preceding attempts at leveraging game-based learning in citizenship education (for example, Selwyn, 2006; Lim \& Chee, 2007). In fact, the Ministry of Education in Singapore commissioned its own game - Statecraft in 2008. The game-world was set in a historical context, with the scenarios taking place in ancient China and India. There were three main differences between $\mathrm{Li}$ ' Ttledot and existing games that were organised around the concept of threats and responses. First, $L i^{\prime}$ Ttledot was developed to somewhat resemble Singapore's historical and social background. This made the game unique as it provided the opportunity for the teacher to draw parallels between $L i^{\prime}$ Ttledot and Singapore. Second, the objectives of the game were also aligned to the 2006 Primary Social Studies syllabus, which focused on process inquiry, communication, participation, and critical and creative thinking. Thus, the learning objectives of the game would be directly relevant to the existing Social Studies curriculum in terms of nurturing thinking skills. Third, Li' Ttledot is a fictitious island and teachers are able to create new scenarios using a BackOffice module. This allows teachers to upload content that is relevant to current affairs and in particular, challenges that Singapore might be facing. Teachers are also able to upload multiple-choice questions, videos and newspaper articles to refresh the content that students will learn in the course of the game.

\section{Theoretical foundation}

Literature on the use of videogames to support learning is extensive; the range includes Billen's (1993) work on games and cognitive development, Rieber's (1996) study on microworlds and simultations, and Quinn's (2005) intervention leveraging elearning. From this body of research, the seminal writings of Jonassen and Reeves (1996), Gee (2003), Prensky (2005) and Shaffer (2005) have emerged as defining the parametric understandings in this broad field. Arising from the latter authors' discussions on neo-Vygotskyian social-constructivism, identities and epistemic frames, the theoretical orientation of the $\mathrm{Li}^{\prime}$ Ttledot learning program can therefore be circumscribed in terms of at least two strands, namely: the 'teaching' of citizenship, and game-based learning and identity (re)construction. These will now be considered in turn.

\section{The 'teaching' of citizenship}

In his seminal thoughts on citizenship education in 1984, Blyth described three lenses through which the issue might be approached, namely:

- Education about citizenship: "I learn what citizenship is all about (but it does not necessarily follow that I will practice what I have learnt)"

- Education through citizenship: "I learn by performing civic-minded acts (but just because I do certain things doesn't mean I am mindful of my intent, I may be just going through the motions)" 
- Education for citizenship: "I learn about citizenship so that I can grow into being a good citizen. The purpose of such education is to guide me towards being an effective and contributive member of my communit(ies)"

The core design principle was thus "to engender citizenship discussion and reflection as part of a more fundamental developmental trajectory of identity construction" (Lim \& Chee, 2007). This principle was informed by Selwyn's (2006) framing of games to present scenarios to make citizenship education meaningful for teaching and learning. By allowing students to make key decisions in the game, the activity would become more student-centred and students are empowered to chart their own progress through the game as they shape the eventual outcomes.

\section{Game-based learning and identity (re)construction}

Much of the effectiveness of interventions such as those described in the preceding section depends on the user experience within the learning environment. Turkle (1995) has made a compelling case that:

[w] hen we step through the screen into virtual communities, we reconstruct our identities on the other side of the looking glass. This reconstruction is our cultural work in progress (p. 177).

This 'cultural work in progress' therefore describes how the in-game learning environment has a significant impact on players' identities as they interact with nonplayer-characters. The affordance of each player to shape the narratival trajectory of his or her respective avatars makes for a compelling learning environment beyond that which might normally be possible in a classroom setting. Thus, these game spaces have the potential to profoundly affect the construction, destruction and reconstruction of each player's identity.

Gee (2007) has described three distinct identities which come into play when one operates as avatar within a game. First, the player brings his or her real world identity, and this is the person as he or she is known in the real world. Second, the game also offers a virtual identity, represented by the character one plays in the game. Third and most critically is projective identity. The projective identity amalgamates elements from within the player's 'off-game' world (such as the player's prior knowledge, intentions, dispositions and culture) with aspects of the in-game world - as delimited by the parameters set by the game designer - to form a blended, projected character. This conflation between the player and his or her virtual persona as they jointly enact a trajectory of experience within the game space creates not only a sense of 'being there' (embeddedness), but - most importantly in the context of citizenship education - a sense of being (first-person embodiment in the world).

The intervention emplaced the bespoke videogame within a wider curricular design involving more traditional forms of learner-interaction in the classroom. Particularly critical in this design were the post-game dialogic interactions between teacher and learner. This design leveraged the projective identity formed through the learner's operation within the game to facilitate the appropriation of a set of values, which might then subsequently inform the learner's post-game decision-making.

The game play involved students making decisions on how to attack or defend the island of $L i^{\prime}$ Ttledot and this allowed teachers to later draw parallels to Singapore's own defence. 
Such a mirrored, scenario-based learning approach involved teachers creating a fictitious event within the game, which had the potential to reflect an actual event. By eliciting comparisons between these scenarios and daily issues, teachers would be able to provide students the opportunity to analyse problems from different perspectives. Such dialogic interactions are consistent with Kiili's (2008) recommendations that teachers play critical roles in scaffolding the learning experiences derived from ingame decision-making.

The identities assumed by learners within the learning environment also allowed them to collaborate and make decisions within a 'safe to fail' environment. Figure 1 shows how students' rich in-game experiences might eventually be translated into practical lessons in the 'real world'.

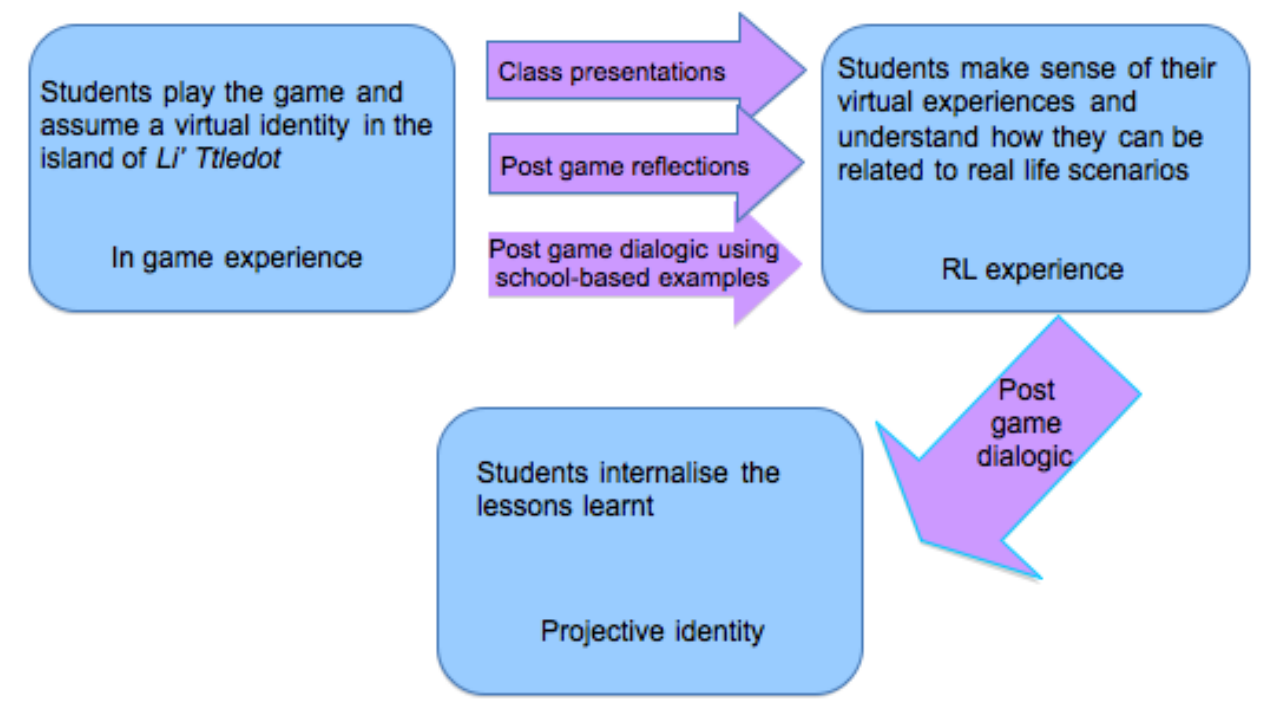

Figure 1: Conceptual framework undergirding the $L i^{\prime}$ Ttledot learning program

The technological construct of the game itself was therefore situated within a wider pedagogical philosophy, namely: using school-grounded examples during the postgame dialogic activity (facilitated by question cards which had game-effects on one side and practical questions linking the respective effects to the real world on the obverse) to help learners abstract the principles and values to performance in real life. The in-game collaborative tasks provide the mediatory scaffold to assist in the abstraction to the values of National Education and this allowed for meaningful discussions in the post-game activities. This wider pedagogical philosophy is elaborated upon in the following section.

\section{Description of the game and its associated curriculum-program}

The intervention was carried out between July and August 2011, among a class of thirty-one pupils from a Grade Five class (eleven-year-olds), in a primary school in Singapore. Sessions were held weekly, over durations of thirty-minutes to an hour (subject to timetabling constraints). 
Before students were brought into the computer laboratory to play Li' Ttledot, the teacher introduced the game and emphasised the ground rules for gameplay. The class was divided into groups of five, each corresponding to one of the five aspects of Total Defence (Civil, Social, Psychological, Military and Economic). Each group would then be paired with another, in a protagonist-antagonist manner - that is, a group of five 'attackers' would be pitted against a group of five 'defenders'. Each student would then take on a role, for example, 'Social Attacker' or 'Civil Defender'. The teacher would then remind students that the program would not consist only of playing the game. The actual operation of students within the game itself would be for an hour, with the remaining time spent in-class, with the students engaging in post-game reflections and discussions, facilitated by their teacher. Specifically, students discussed the strategies employed in order to complete the missions.

The game itself began with an introduction to the island of $L i^{\prime}$ Ttledot and how it had enjoyed peace for many generations. The return of the Rogue Wolfpac, however, threw the nation into disarray as its five members tried to disrupt the peace that $\mathrm{Li}^{\prime}$ Ttledotians had enjoyed. Amidst this crisis, the country turned to the Super Eagles, an elite group of five special agents whose expertise was in the five areas of Total Defence. Each player - attacker or defender - would assume an in-game identity that specialised in one particular aspect of Total Defence. Their respective roles would enable them to carry out different game-effects as they attempted to influence the happiness level of the country.

In the introductory mission, students - in the role of the different agents - explored the game-space to look for clues to learn more about $\mathrm{L}^{\prime}$ Ttledot and the specific area of Total Defence that they were specialising in. For example, the Economic Attacker would look for clues that provided information related to the history of Li' Ttledot and its economy. Figure 2 depicts this differentiated in-game activity.

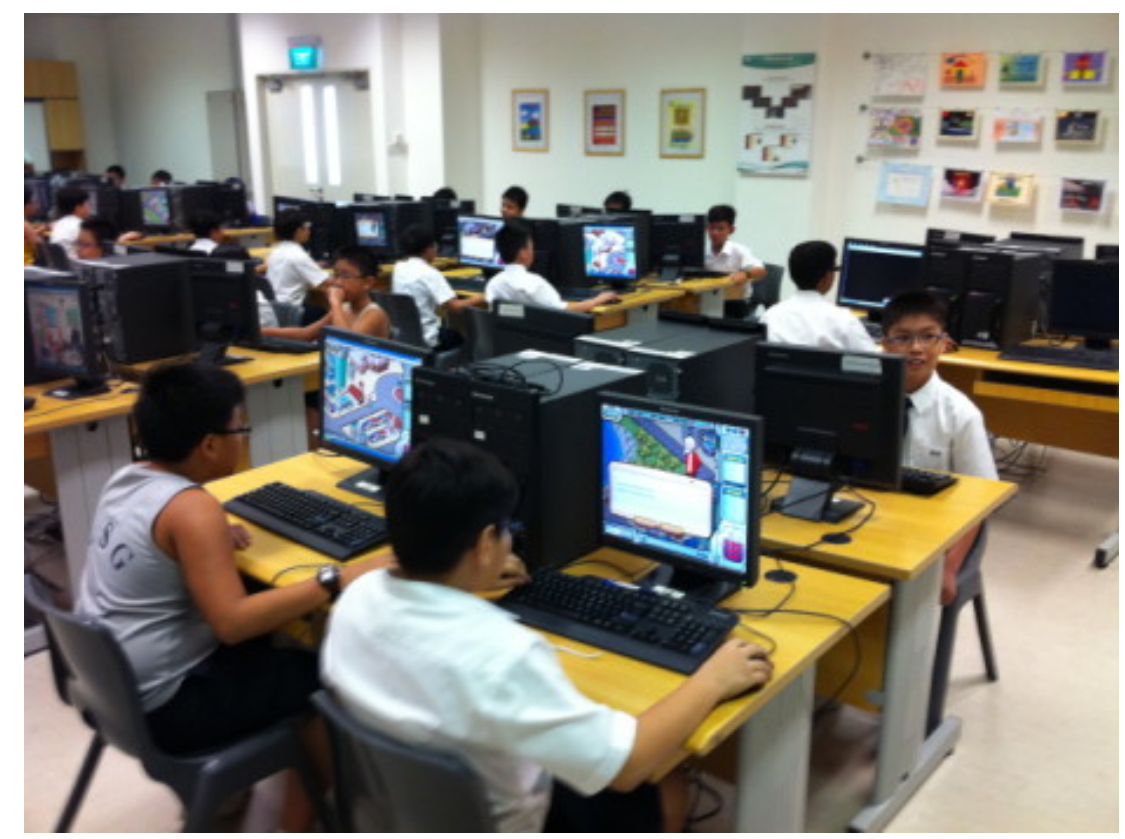

Figure 2: Differentiated in-game activity within student groups 
The unique point about the attacker's role is that it required the player to play the role of the antagonist. In a sense, this involved having to analyse the questions very carefully to provide the 'wrong' answer. For example, when the attackers are asked how they could go about encouraging people to save money for a rainy day, a nonplayer character could remind them that their objective would be to get people to waste money. Mission points were awarded for appropriate answers. These mission points unlocked more powerful effects that could be subsequently used to affect the happiness level of the country more significantly.

In the course of the game, players were also presented with challenges for which they would need to call on their knowledge of subjects such as English, mathematics and science. These activities tested their analytical, comprehension and generative skills, while providing students with opportunities to earn the points they needed to execute subsequent game-effects. Challenges and puzzles were employed in a similar manner by Seagram and Amory (2005) and by Foko and Amory (2008), in order to surface students' misconceptions. The varied way in which the content was presented challenged students to think creatively as they went about problem-solving. These are important 21st century dispositions that students need to appropriate for themselves.

After having played the game, students were given guiding worksheets on which they had to recall and describe at least two missions which they chose to undertake, and provide three different perspectives on each, namely: those of the culprit, the victim and the bystander. Figure 3 illustrates this stage of the intervention. Students were then required to craft presentations collaboratively to analyse the missions in the course of the game, from these perspectives.

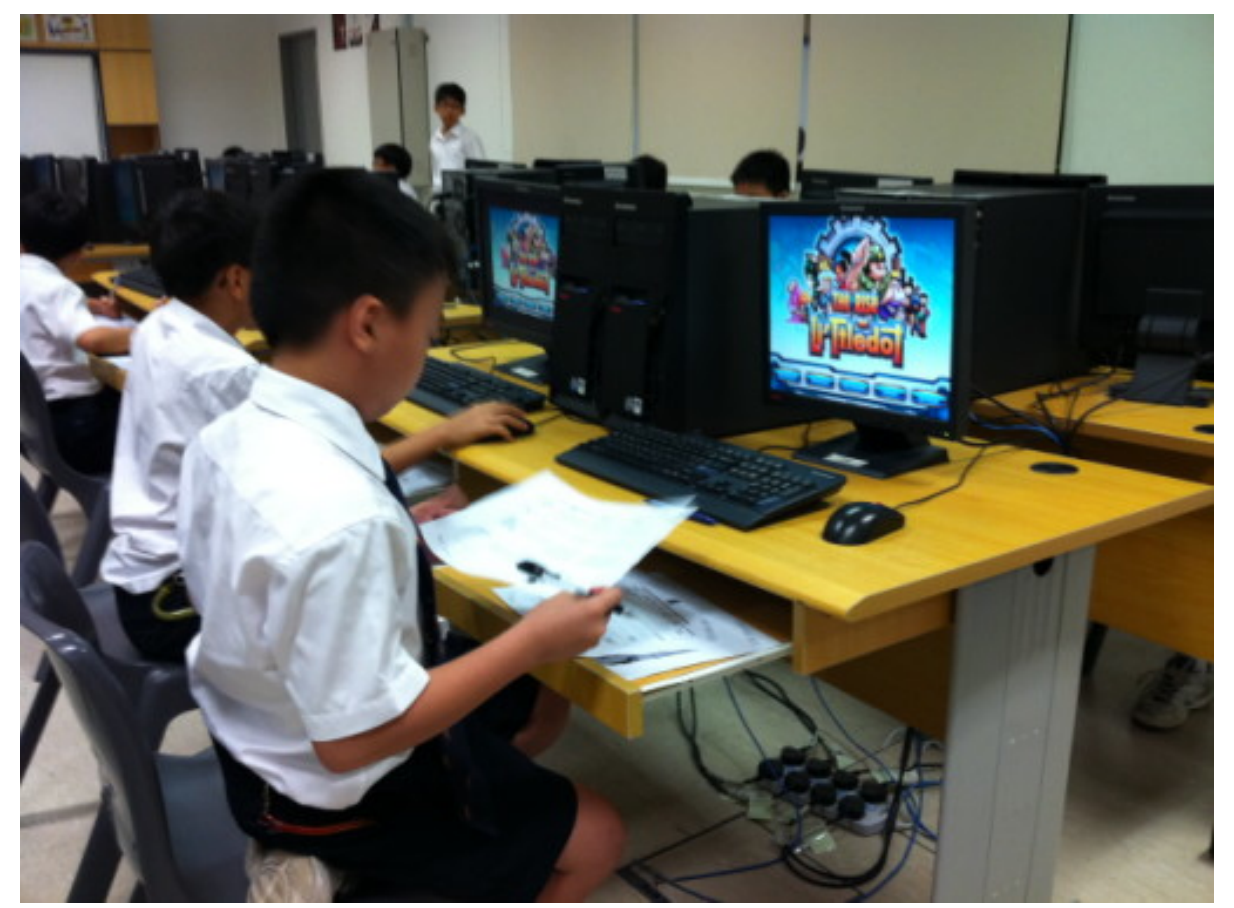

Figure 3: Students documenting their in-game decision-making on the worksheets 
At the end of the presentations, the teacher lead the class in a discussion facilitated by question cards that drew parallels between the island of $\mathrm{Li}^{\prime} \mathrm{Ttledot}$ and Singapore. For example, if a player had carried out a game-effect that involved destroying the financial center of $\mathrm{Li}^{\prime}$ Ttledot, it would provide the teacher with the opportunity to ask what would happen if Singapore's central business district were subject to a terrorist attack. The rich discussions that followed were provocative and encouraged students to think deeply about what citizenship meant to them and how everyone had a part to play in Total Defence.

\section{Methodology}

This research relied on qualitative methods that included audio recordings of selected students during the game, video recordings during student presentations, a video recorded in-depth interview with selected students after playing the game, students' self-reflection forms, and informal conversations with students and the teacher over the course of the program. All audio and video recordings were transcribed for analysis while students' reflection forms and pre- and post-surveys were recorded and archived. Observation notes were taken at every lesson for this program and this allowed us to also capture informal conversations among students pertaining to the game. The data analysis process was iterative and triangulated among various data sources for verification and analysis. In this way, the analysis of the three stated aims of the research, namely: citizenship education, thinking skills and collaboration, was rendered more nuanced and accurate.

The research was conducted at a government-aided elementary school and focused on 11-year old students. Prior to the program, the students were briefed about the purpose of the research and informed that their responses would be kept confidential. The class was then divided into groups of five with each student playing a specific role as either an attacker or defender of $L i^{\prime}$ Ttledot. There were two groups where there were insufficient numbers to make up five and the data gathered from these two groups were included for the general surveys but not during the in-depth interviews.

To ensure that students were aware of the technical requirements of the game, the teacher conducted an initial tuning-in session and students were briefed about the objective of the game and the various game controls. There was also a debrief session during which students could ask any questions that they might have had regarding the game play.

During the program, students were asked to complete a pre-survey before playing the game and then complete a self-reflection form and post-survey after the game. Ten students were selected for the post-game interview and they were identified based on their role in the game such that both attackers and defenders were represented. During the interview, the students' responses pertaining to citizenship education, thinking skills and collaboration were noted and triangulated with the data from reflection forms and pre- and post-surveys.

\section{Results and discussion}

The main sources of data gathered came from pre- and post-surveys, audio recordings of selected pairs of students during the game, video recording during student presentations, students' self-reflection forms and an interview session with the same 
group of pupils who had earlier consented to having their gameplay recorded. The data was subsequently reviewed and triangulated to inform understandings of the effects of the intervention on its original three aims, namely: citizenship education, thinking skills and collaboration.

\section{Citizenship education}

One aspect in which the intervention was helpful was in providing shared experiences upon which wider conversations could be initiated. For example, there was a gameeffect that the 'Psychological Attacker' could carry out, namely to "carry out a biological attack on all schools in Li' Ttledot and cause mass hysteria amongst school children". During the post-game dialogic discussion, the teacher used the question cards and drew students' attention to the possibility of such an attack occurring in their school. The following exchange was observed:

Teacher: Do you know what to do in the event of a chemical or biological attack in your school?

Student: Hide. Inform other people. Break the glass and press the fire alarm.

Such dialogue provided a very useful opportunity for the teacher to then discuss the importance of civic responsibility in the school and to recapitulate the proper emergency procedures that the students should be aware of.

Similarly, Table 1 presents data from the pre- and post-surveys showing that after having played the game, students had a stronger sense of confidence in making a difference in society and in the lives of others. The majority of pupils understood that it was important to consider the greater good in decision-making and that every citizen could make a positive difference to the country.

Table 1: Change in participants' sense of civic responsibility after the intervention

\begin{tabular}{|l|l|l|}
\hline \multicolumn{1}{|c|}{ Statement } & \multicolumn{1}{|c|}{ Pre-intervention } & \multicolumn{1}{c|}{ Post-intervention } \\
\hline $\begin{array}{l}\text { I feel that I can make a positive difference } \\
\text { to my country }\end{array}$ & $\begin{array}{l}76 \% \text { answered either } \\
\text { 'agree' or 'strongly agree' }\end{array}$ & $\begin{array}{l}90 \% \text { answered either } \\
\text { 'agree' or 'strongly agree' }\end{array}$ \\
\hline $\begin{array}{l}\text { If people did what was best for } \\
\text { themselves, our world would be a happier } \\
\text { place }\end{array}$ & $\begin{array}{l}44 \% \text { answered either } \\
\text { 'disagree' or 'strongly } \\
\text { disagree' }\end{array}$ & $\begin{array}{l}53 \% \text { answered either } \\
\text { 'disagree' or 'strongly } \\
\text { disagree' }\end{array}$ \\
\hline
\end{tabular}

The post-intervention change in students' responses to the latter question was especially telling, bearing in mind that the participants were only eleven years of age. That the majority of the class was able to see the lie in an 'every man for himself' or 'Tragedy of the Commons' ethic at such a relatively young developmental age should be extremely encouraging to anyone with a stake in education.

In general, this ability to adopt perspectives other than that of self was evidenced by other aspects of the intervention. During the presentations after the game, students were encouraged to analyse the missions they undertook from three different perspectives. To draw lessons from these perspectives, the teacher continued using the question cards to elicit parallels between game-play and Singapore. 
For example, the Psychological Attacker carried out an effect that "spread rumours that the existing government is not capable of managing $L i{ }^{\prime}$ Ttledot". Drawing on this game-effect, the teacher facilitated a discussion that included the following exchange:

Teacher: Would you be concerned if people started spreading rumours that your school was not a good school?

Student: Yes, our morale will go down and our work will go down too.

The teacher then went on to discuss how the stability of the country also affected the economy because investors always needed to have the assurance that their investments would not be affected by political or social crises.

Such evidence that the students were able to draw lessons from their in-game experience, was corroborated during the post-game interview and survey. One student commented that "... when you use it in a game, in another world, which you can use and then you can apply it in real life..." while another responded that playing $L i^{\prime}$ Ttledot "allowed me to learn more character trades [sic] and made me learn that the Singapore defences are very important".

Broadfoot (2000) and Brown (2006) have observed how such post-activity reflection is a powerful means of appropriating enduring understandings from learning experiences. Indeed, this was one of the deliberate design elements in L $i^{\prime}$ Ttledot; students could key in their reflections after they accomplished certain missions. At the end of the game, students would also complete a self-reflection form. This facilitated the students learning from their in-game experiences and encouraged them to link them to their daily life. Many of the students who played $L i^{\prime}$ Ttledot felt that these missions or effects in the game could actually happen in our daily lives. In the self-reflection form, 93.1\% of students answered 'yes' to the question "Do you think it is possible for some of the missions or effects in the game to actually happen in our daily life?"

One particular incident that the teacher was able to make specific reference to was the vandalism of a train in Singapore when two vandals managed to cut through security fencing and sprayed graffiti on the trains. Interestingly, the students initially responded that the physical security of the area should be enhanced but later added that a movement against vandalism could be initiated so that people would understand why it was wrong to vandalise property. From physical solutions, the students were able to now offer social solutions that prevented the offence from being committed in the first place. This showed that the value of the game did not cease when students stopped playing it but actually continued into the dialogic lesson and students' daily lives.

As the dialogic lesson progressed, and the teacher drew more parallels between $L i^{\prime}$ Ttledot and Singapore, students were also able to make reference to events outside Singapore. When the teacher asked if the attacker's game-effect of bombing Li' Ttledot's financial district was possible in real life, students were able to recall the devastating events of 2001 and realise how real the threat of terrorism was. Students were also able to describe how such events could potentially devastate Singapore's society and economy if they ever were carried out. Thus, students highlighted the need for increased public awareness of Total Defence and to encourage more community involvement programs in schools so that young children would have a heightened sense of civic responsibility when they grew older. 


\section{Thinking skills}

As already discussed, the ability to analyse problems from different angles is an important thinking skill, if students are to become more civic-minded. While playing $L i^{\prime}$ Ttledot there were ample opportunities for students to exercise such analytical thinking skills. Their implicit decision-making strategies were then made explicit in students' presentations after the game, when they needed to discuss what missions they had accomplished and evaluate the consequences to the people around if they were actually carried out in real life. One particular mission, 'Bully bash', asked players what they would do if they saw someone innocent getting bullied. After the game, the students were then encouraged to think about this problem from the bully's perspective, followed by the victim and then the bystander. In this structured approach, students were able to articulate how each person might feel and thus realise how everyone, even a bystander, can play a part in ensuring social justice.

Responsible citizenship includes a critical, questioning disposition. One example of how gameplay in Li' Ttledot, attempted to promote such an orientation was to present students with a mission in which the attackers promoted a sense of complacency among the citizens and encouraged the creation of a welfare state. During the postgame dialogic session, the teacher made reference to this mission and asked students whether a welfare system would be suitable for a country such as Singapore. A lively discussion ensued. While it was important not to neglect the needy and less fortunate in every society, students were also made aware that - at least within the context of Singapore - there was a need for every citizen to work hard and contribute to the progress of the nation, without being complacent and relying on state-handouts.

While the consensus was that a welfare system would not be suitable for Singapore, the teacher also asked what might happen if an employer was forced to retrench employees. Using the reflection form, a student responded that the employee would feel very sad and need to exercise greater caution in spending money. The employer might be sad to lose a good and experienced member of the staff but for the greater good of the company, painful decisions had to be made. In this case, it was difficult for the bystander to do anything as heor she might not be able to help either party. In using this structured approach, the student was able to analyse the issue from different perspectives and arrive at a more nuanced stance, than if only one perspective had been considered.

\section{Collaboration}

The game design of $L i^{\prime}$ Ttledot emphasised the importance of teamwork, as every player had a part to play in influencing the happiness level of the country. If any individuals were not contributing, the entire team would be affected. As each player was in charge of a particular pillar of Total Defence, this made students more aware of the need for every pillar to be strong and for every citizen to contribute to all pillars instead of focusing solely on one. Prior to playing Li' Ttledot, 37.9\% of students believed that "The Singapore Civil Defence alone (could) handle our Civil Defence". However, after playing the game, only $7.1 \%$ of students believed that this was so. Clearly, the students had by then realised the importance of every citizen playing one's role in maintaining Civil Defence in the country.

While playing the game, players were conscious not to let their opponents know their game strategies. Once the game started, students started collaborating at different 
levels, from learning to play the game from each other to strategising to accumulate points. During the interview session, one student articulated the experience such that in the course of playing the game "you get to learn character traits from other players also, for example, in teamwork, you helped each other in different ways". In this way, students were able to practise their collaborative skills as they worked together towards a common goal.

\section{Limitations}

We acknowledge the relatively small sample size of this study, with its consequent implications on the dearth of statistically-significant quantitative data. Further, as the intervention was designed to be enacted in an authentic environment which did not interrupt regular class lessons as part of the state-mandated curriculum, it did not stipulate particular time periods that the teacher had to set aside in order to facilitate the lessons. Instead, the social studies periods that the school had already planned for the entire level were used. This meant that there were occasions when scheduled sessions for the intervention were postponed.

\section{Conclusion}

Citizenship education is a challenging topic to approach with young learners as they have not reached sufficient developmental maturity to relate the values of social and civic responsibility to their daily lives. $L i^{\prime}$ Ttledot attempted to address this difficulty by providing a rich in-game environment that had various scenarios and activities from which parallels might be drawn to Singapore. During post-game activities, students were encouraged to make explicit these connections, and to analyse their in-game mission-enactments from different perspectives. Success in the game also hinged on the collaborative participation of fellow secret agents and thus it was important for every player to contribute to the overall group effort.

The research into the use of this game at Grade Five (eleven year olds) suggests that the use of such interventions could be useful in stimulating learners' own insights about citizenship. As students reflected on their in-game experiences and drew parallels with their daily lives, the teacher was able to facilitate a rich post-game dialogic session to make sense of abstract principles related to citizenship education. As the discussion also drew on students' school-based experiences, there were adequate scaffolds built around students' learning.

As $\mathrm{Li}^{\prime}$ Ttledot emphasised teamwork, it was important for students to build effective group processes that facilitated their collaboration. The success of the group did not depend solely on any single character but on the team as a collective whole. This allowed valuable lessons to be elicited from the in-game experience, as the teacher was then able to bring students to their own realisations about the relationship between citizenship and social and civic responsibility. This emphasis on empathy and perspective-taking provided valuable opportunities for students to construct their own identities as budding citizens.

Good citizens are not born but are nurtured; yet citizenship - as in much of values education - cannot be explicitly taught. This paper suggests that one way in which the nurturing process could begin from a young age might be by leveraging the affordances of game-based learning, so that students might be presented with 
authentic opportunities to analyse complex issues from a variety of perspectives. Given the wide exposure of young learners to online games, this suggests some credence be given to game-based learning in effective citizenship education.

\section{Acknowledgments}

The work reported in this paper is funded by from the award of a Ministry of Education Innovation Fund. More information about the intervention - including screenshots from the game - can be found at Ong, M. Y. C. \& Lim, K. Y. T. (2012). The Rise of $\mathrm{Li}^{\prime}$ Ttledot: A study on how game-based learning can promote national education, thinking skills and collaborative learning. International Conference on Teaching and Learning with Technology, Singapore, 27-30 March. http://www.ictlt. com/ files / 2012-03-30\% 2018:20:20_the-rise-of-li-ttledot-a-study-on-how-game-basedlearning-can-promote-national-education-thinking-skills-and-collaborativelearning.pdf

\section{References}

Annan, K. (1998). Secretary-General's statement at the opening of the World Conference of Ministers Responsible for Youth, 8 August.

http:/ / www.un.org/ events/youth98/speeches / sgyouth2.htm

Billen, A. (1993). Could it be the end for Super Mario? The Observer, 27 June.

Blyth, A. (1984). Industry education: Case studies from the North West. In I. Jamieson (Ed.), We make kettles: Studying industry in the primary school. Longman, London.

Broadfoot, P. (2000). Comparative education for the 21st century. Comparative Education, 36(3), 357-371. http: / / dx.doi.org/10.1080/03050060050129036

Brown, J. S. (2006). New learning environments for the 21st century: Exploring the edge. Change, 38(5), 18-24. 10.3200/CHNG.38.5.18-24 [also at http: / / net.educause.edu/ir/library/pdf/ff0604S.pdf]

Foko, T. \& Amory, A. (2008). Social constructivism in games based learning in the South African context. In World Conference on Educational Multimedia, Hypermedia and Telecommunications 2008 (pp. 5757-5764). Vienna, Austria: AACE. http: / / www.editlib.org/p/29180

Gee, J. P. (2007). What video games have to teach us about learning and literacy. New York: Palgrave Macmillan.

Jonassen, D. H. \& Reeves, T. C. (1996). Learning with technology: Using computers as cognitive tools. In D. H. Jonassen (Ed.), Handbook of research on educational communications and technology (pp. 693-719). New York: Macmillan.

Kiili, K. (2008). Teacher's role in media detective game: Communication through non-player game characters. In World Conference on Educational Multimedia, Hypermedia and Telecommunications (pp. 5248-5255). Chesapeake, VA: AACE. http:/ / editlib.org/p/29103/

Lim, K. Y. T. \& Chee, Y. S. (2007). In stable orbit: An initial assessment of dispositional changes arising from learning using the citizenship education videogame Space Station Leonis. In T. Hirashima, U. Hoppe \& S. S. C. Young (Eds.), Proceedings of the 2007 conference on Supporting Learning Flow through Integrative Technologies, pp.245-252. Asia-Pacific Society for Computers in Education, IOS Press Amsterdam. 
Prensky, M. (2005). In educational games, complexity matters. Mini-games are trivial - but "complex" games are not. An important way for teachers, parents and others to look at educational computer and video games. http: / / www.marcprensky.com/writing/PrenskyComplexity_Matters.pdf

Quinn, C. (2005). Engaging learning. Designing e-learning simulation games. San Francisco: Pfeiffer, John Wiley \& Sons, Inc.

Rieber, L. (1996). Seriously considering play: Designing interactive learning environments based on the blending of microworlds, simulations and games. Educational Technology Research $\mathcal{E}$ Development, 44(2), 43-58. http:/ / link.springer.com/article/10.1007/BF02300540

Seagram, R. \& Amory, A. (2006). An assessment of learning through the use of a constructivist learning environment. In E. Pearson \& P. Bohman (Eds.), World Conference on Educational Multimedia, Hypermedia and Telecommunications 2006 (pp. 2165-2172). AACE. http: / / www.editlib.org/p/23306

Selwyn, N. (2006). Citizenship, technology and learning - a review of recent literature. Futurelab Series Report 3 update. Bristol, UK. http: / / archive.futurelab.org.uk/resources / documents / lit_reviews/Citizenship_Review_update.pdf

Shaffer, D. W. (2005). Epistemic games. Innovate, 1(6). http:/ / innovateonline.info/pdf/vol1_issue6/Epistemic_Games.pdf

Sim, J. B.-Y. \& Print, M. (2005). Citizenship education and social studies in Singapore: A national agenda. International Journal of Citizenship and Teacher Education, 1(1), 58-73. http: / / www.citized.info/ ejournal/Vol\%201\%20Number\%201/004.pdf

Turkle, S. (1995). Life on the screen: Identity in the age of the Internet. Simon \& Schuster, NY.

Authors: Dr Kenneth Y. T. Lim, Office of Education Research

National Institute of Education, Nanyang Technological University

Email: voyager@mac.com

Matthew Y. C. Ong

Ministry of Education, Singapore

Please cite as: Lim, K. Y. T. \& Ong. M. Y. C. (2012). The Rise of Li' Ttledot: A study of citizenship education through game-based learning. Australasian Journal of Educational Technology, 28(8), 1420-1432. http: / / www.ascilite.org.au / ajet/ ajet28/lim-kyt.html 